\title{
The Exploration of Sports Cultural Transmission in University Tennis Teaching
}

\author{
Hezhen Wang ${ }^{1, a}$ \\ ${ }^{1}$ Hubei University of Automotive Technology, Shiyan, Hubei Province, China \\ a51072630@qq.com
}

Keywords: Universities, Sports culture, Tennis teaching, Exploration

\begin{abstract}
Tennis movement's influence on the construction of campus sports culture is mainly manifested in three aspects: spiritual level, material level, system and method level. Tennis culture has rich connotation, through the study of tennis culture courses, which can expand students' knowledge, and improve the students' comprehensive quality. Tennis teaching is not only to make students love tennis, tennis teaching can cultivate students' healthy positive upward spirit, promote the development of students' comprehensive quality.
\end{abstract}

\section{Introduction}

Tennis as a health, elegance, and fashion sports has attracted the attention of a great number of colleges and universities, make more people know about tennis sport in colleges and universities and tennis culture, as well as the construction of campus sports culture in one of the important part [1]. Tennis sport in colleges and universities have made great development in recent years, is the students love and favor, its itself is the cultural connotation, enrich the campus life of students at the same time, also to the development of students' behavior and personality has a positive impact.

\section{College tennis teaching and the relationship between physical culture and sports culture connotation}

Tennis and sports culture of relations and connections. First of all, the tennis culture is a component part of the sports culture. Sports culture to promote personal supremacy, emphasizing the perfect individual value, pursuit beyond external and rational thinking, it mainly depends on the culture environment in the process of sports development; The characteristics of sports culture is a progressive and open absorbent, under the commodity economy open cultural environment, to form the sports cultural pursue honors the beauty of a kind of power [1]. Sports culture, on the other hand, is a kind of self-reliance, adventure, meet difficult straight on pioneering spirit. For tennis, it is a recreational sport and keeping fit, it has been involved in the school's daily life, especially in colleges and universities sports activities, become an organic part of college campus culture.

Analysis of the college tennis teaching function and meaning of cultural transmission. Cultural transmission, the transmission is a kind of value and spirit, for people to look at things and right thing has an important guiding role. Culture dissemination of tennis teaching, can help students set up tennis movement of the target, and form the correct values. Once the students recognize and accept the concept of tennis culture and value, is the same with other positive, healthy and progressive culture, play a positive role to their behavior, and a daily norms of behavior, the formation and standardize students accept the tennis culture the way of thinking and moral ideas. This can cause an invisible effect on the students, to student's behavior and cognitive ability has the very good role in promoting [2]. Transmission of tennis culture, strengthen the sports practice exercise is helpful to the student, students can also feel the deeper pleasure of tennis. Through the tennis teaching, the students can gain a better understanding of tennis, and really like best tennis movement, and then put the positive, focus and optimistic spirit of tennis to your own life.

The connotation of campus sports culture. Campus sports culture is the campus culture and sports culture both promote and influence each other, fusion, osmosis, developed, is in a certain social 
politics, economy, culture, education, sports and other conditions on, by the staff all the teachers and students together create in practice of colleges and universities sports spirit and the sum of wealth. Sports culture as a kind of culture, also has a history of social sex and age. University sports culture is an important part of campus culture, is the height of the combination of education and sports, is the physical education thought and the practice of the inheritance and development of history [3]. Campus sports culture as one of the forms of social sports culture, has a distinct personality characteristics, it comes from social culture, breeding development background of social sports culture, and has the characteristics of university sports culture, the sports culture is the soul of campus spirit. Colleges and universities sports culture has extensive profound connotation, including the spirit level, system level and material level.

Sports culture is a kind of friendship, respect, confidence and the spirit of the heritage and development, it is a kind of unity, mutual assistance to participate the collection of the human spirit to carry forward, it can promote understanding between people, friendship, mutual aid, is helpful to enhance the trust between the people [3]. Campus, as a kind of the development of sports culture and carry forward the ground, for its sports culture inheritance plays an important role. Sports culture is a kind of education culture, but also a culture of learning, it is advantageous to the student learn to cooperate friendly attitude, forming a modest learning attitude. From another perspective, the connotation of sports culture is a kind of positive, grasped the nettle of the enterprising spirit, it can give people continue to pursue their dreams of power and the persistence of perseverance, spurred the growth progress continuously in the enterprise.

Tennis culture is an extension of the sports culture. Tennis since birth, such as the rules of tennis etiquette, equipment and are in the process of continuous improvement and progress, in tennis culture with the development of tennis sport has been improved. Since each region, the different national indigenous culture, make the region there are big differences of tennis culture, mainly reflected in its different forms of expression.

Just reflected the tennis world four big open regional culture of different, first of all, the French romantic and sexy, and my starlight in the us open and luxury, in one hundred, growth of the Australian open, wimbledon noble sport traditional beauty, fans from all over the world are making the crazy love [4]. By above can see, the tennis culture can be summarized as the different parts of the world, regional population through engaged in the activities of tennis, unceasingly summarizes, innovation and development of a collection of all kinds of material and spirit. The passion of competitive tennis sports raised its view, makes the public for tennis can produce larger interests and hobbies, this to the development of tennis sport at all levels have played a very good protection effect, at the same time in the system and also on the behavior of people form the role of a specification. Tennis culture connotation, can understand from the perspective of tennis sport as tennis professional theory, the use of techniques and tactics, and local customs and the floorboard of the combined system. Enhancing the value of tennis sports groups sharing improve tennis sports socialization is culture the essence of the content and target.

\section{Tennis sports of university sports culture influence}

The influence of tennis sport on college students' sports fashion. Sports fashion is popular sports habits, culture, mainly including attitude, sports population. Good sports fashion, can make the campus activities is full of vitality, active campus life spirit atmosphere, also helps to improve campus relationship between teachers and to promote and strenuously emotions, edify sentiment and the formation of good school spirit and study style [5]. An important feature of tennis is trust game, game should have striven for victory in the war of the body state of mind, and culture, to develop the tennis match, to win without pride and lose with grace, respect each other and peer collaboration, etc. Only do this, can out of style, race out of level, strive for victory. Exquisite skill is important, but also can make people form good sports fashion charm, both benefit from chapter makes sport become real gentleman movement.

The influence of tennis on college students' sports target. Sports goal, is what sports to achieve position and participate in sports to the desired direction [4]. Colleges and universities set up the 
correct sports goal, students increased pressure on participation in tennis and motivation, inspire their passion.

The influence of tennis sport on college students' sports knowledge. Tennis knowledge is to know the results of tennis activities or crystallization. Can enable students to master more knowledge of tennis, tennis broaden students' knowledge, at the same time improve the students' interest in tennis and understanding [5], let students really understand the tennis sport bring happiness to people, make students form good sports consciousness and lifelong sports consciousness, so as to promote the prosperity and development of the campus sports culture in colleges and universities.

The influence of the tennis sport on college students' sportsmanship. College sports spirit, refers to the colleges and universities under the certain social historical conditions, in order to achieve the education goal, step by step in the construction of campus culture in the long-term accumulation, integration, refining, reflect the school university student fitness goals, ideal, faith and sports the traditional values and code of conduct and group consciousness. Students can be cultivated in the process of tennis sports spirit, enhance the students' competitive consciousness and motivate their initiative, cultivate their strong will, enhance their confidence and courage to overcome the difficulty; Cultivate their spirit of collaboration and law-abiding morality [5]; Through the tennis movement to improve campus sports spiritual culture, to play the unique education function of college campus sports culture, enable students to comprehend the meaning of the spirit, appreciate life, prepare for life in the future development.

\section{College tennis sports material impact on the campus sports culture}

Tennis venue, equipment, construction of campus sports culture. Tennis is to the field dependence of higher sports, tennis venue, equipment construction is courses in tennis, tennis practice and to hold all activities such as tennis, and tennis court to the smooth progress of tennis teaching in colleges and universities is the main "hardware", it is the basic material safeguard of tennis activity, it is a most important place for campus tennis culture dissemination, directly affects the degree of campus tennis culture development [6].

Tennis teaching conditions influence on campus sports culture. In tennis sport consumption is convenient, the school can provide venues, but the tennis racket and ball in the auxiliary appliance such as the need to buy, can through the student to the tennis sport consumption level is very real and very direct response student interest in tennis sports and hobbies [6]. Tennis books and materials, tennis teaching material influence on the campus sports culture books, textbooks, audio and video data is an important way of promoting the students get tennis technology knowledge, is the indispensable auxiliary materials of tennis teaching and learning, it can offer the correct theoretical guidance for tennis teaching, enhance the students' cognitive ability in tennis, and expand the students' understanding of tennis knowledge.

To carry forward to strengthen the teaching of theory of tennis culture. The impact of competitive sports, the ordinary university in teaching for a long time, pay attention to the practice of technology, and ignore the importance of theory teaching, this kind of phenomenon is more common in the tennis teaching. Tennis teaching practice, in the process of physical education teaching contents should include two parts, namely the theory of learning and technology practice. Technology practice can develop the body, and the theoretical knowledge of learning can make students' comprehensive quality is improved, the two works. In the practice of learning and teaching, learning too much emphasis on technology, can lead to poor students of basic level, and cannot have a big harvest and breakthrough [7]. Should be fully aware that in the construction of college tennis lessons, not only should we attach importance to the practice of technology, but also pay attention to the teaching of theoretical knowledge. To the teaching of the basic theoretical knowledge, to the technology practice is complementary, such ability culture deepen students enough for tennis as well as the understanding of the sports culture, make them but not a fan of tennis sport, is a sports culture disseminator.

Efficient tennis lessons to make use of network resources application teaching. The trend of the development of tennis sport in colleges and universities, culture teaching should attach importance to tennis, tennis culture has rich connotation, through the study of tennis culture courses, 
can expand students' knowledge, improve the students' comprehensive quality. First of all, in the teaching of middle school students by knowledge and to understand the history of tennis etiquette knowledge, the ability to student's moral cultivation, the character, the subtle influence of daily behavior habits [8]. Tennis movement in the process of the development of long-term deposit very rich knowledge of history; Including modern tennis equipment, sites, rules change make tennis contains rich cultural knowledge; Tennis tennis tournament organization to promote, in order to improve the more economic knowledge, these knowledge are most students usually don't understand and really want to know, through the understanding of the knowledge in class can easily attract the interest of students, inspire students' love for tennis, voluntary to join in tennis. Second, a good atmosphere and rich knowledge can form the tennis culture phenomenon, make the college tennis sports has a broad mass base, more conducive to long-term development of tennis sport.

\section{Summary}

Tennis culture inheritance and students master the regular pattern of tennis in terms of technology and theory to experiment teaching. Students at beginner's tennis to create a good impression on the later learning and the cultivation of interest is very important. In tennis teaching process to the technology as the main line, combining with the evolution of interpretation of the history of tennis and tennis culture connotation, so that students in mastering the technology at the same time, the profound understanding of the historical culture of tennis. Also in the process of teaching pay attention to students' etiquette and manners, and encourage students to become worthy of the name tennis sports enthusiasts, and is also a tennis sports culture disseminator.

\section{References}

[1] J. Sun, Shandong university tennis sports development present situation analysis and countermeasure research, Journal of Jilin institute of sport, vol. 2, pp.41-47, 2007

[2] G.G. Song, tennis culture communication and teaching research in the college, Liaoning normal university, vol. 1, pp.12-18, 2011.

[3] T.J. Liu, Tennis teaching in colleges and universities sports culture communication discussed, stationary and science and technology, vol.22, pp.101-106, 2013.

[4] H.Y. Yang, Theory of university sports culture construction, education and occupation, vol.9, pp.32-37, 2007.

[5] Y.M. Zhu, About the development of college campus sports culture, journal of Shenyang institute of engineering (social science edition), vol.2, pp.71-75, 2005.

[6] F.F. Yang, Sh.H. Lei, The social culture of tennis sport, Sports and Science, vol.8, 66-71, 2005.

[7] Y.F. Xu, The theory of college students' tennis and physical and mental health, Journal of Zhejiang Normal University, vol.65, 4-9, 2003.

[8] P.X. Lee, Analyze the tennis culture influence on college students, Sports world academic, vol.12, 12-18, 2006. 